
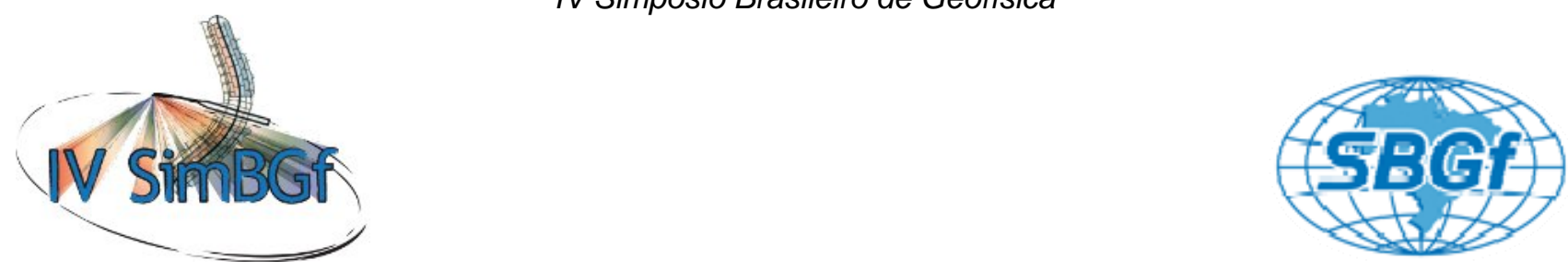

\title{
Evaluation of Morphological Correlation between Free-air Gravity Anomaly and Bathymetry of South-East Brazilian coast
}

\author{
Pavel Jilinski ${ }^{1}$, Sergio L. Fontes ${ }^{1}$, Luis A. Gallardo ${ }^{2}-{ }^{1}$ Observatório Nacional/MCT, Brazil; ${ }^{2}$ University of Western Australia, \\ Australia
}

Copyright 2010, SBGf - Sociedade Brasileira de Geofísica

Este texto foi preparado para a apresentação no IV Simpósio Brasileiro de Geofísica Brasília, 14 a 17 de novembro de 2010. Seu conteúdo foi revisado pelo Comitê Técnico do IV SimBGf, mas não necessariamente representa a opinião da SBGf ou de seus associados. É proibida a reprodução total ou parcial deste material para propósitos comerciais sem prévia autorização da SBGf.

\begin{abstract}
We present the results of a joint image interpretation application to determine morphological correlation between Free-air gravity anomaly (FA) and bathymetric maps. Our method uses angles between gradients, crossproducts values and their statistical distribution as criteria to evaluate correlations. Synthetic models simulating gravitational effect from bathymetric structures were created to test our method. Obtained results allowed us to develop criteria to evaluate correlation between maps. We applied this method to investigate the relations between (FA) and bathymetry maps of South-East Brazilian coast. Method and results are discussed.
\end{abstract}

\section{Introduction}

Correlation between bathymetry and FA provides important information on regional lithosphere isostasy and reflects its thermo-mechanical state (Watts, 2001).

In a stable region we can expect the bathymetry being the main source of the observed FA. Local bathymetric structures within a scale of $100 \mathrm{~km}$ are supported by lithosphere and have a corresponding FA while only larger structures are isostatically compensated (McKenzie, 1976). FA directly reflects the state of isostatic compensation (Audet, P., Mareschal J.C., 2007; Dehlinger, 1978; McKenzie, 1976; Torge, 2003; Watts, 2001) and are strongly correlated with local, uncompensated bathymetry (Franziska and Rummel, 2009). Exceptions could be found in regions with active tectonics or increased heat flux.

There is a variety of approaches to determine the relation between bathymetry and gravity anomalies and isostatic compensation for example wavelet transforms (Audet et. al., 2006; Keller, 2004) or computed isostasy based on Airy-Heiskanen and Pratt-Hayford models (Gottl et al., 2009; Heiskanen, W. 1953).

In our research we used angles between gradients directions and cross-product values as qualitative and quantitative criteria of correlation between FA and bathymetry maps. The advantage of using a morphological approach is that no actual isostatic compensation or Bouguer correction is computed to derive the conclusions. Our hypothesis is that a strong morphological correlation between bathymetry and FA is a criterion for geological stability of the region indicating no inner (deep-crust or mantle) phenomena occurs, helping to interpret crustal structure. We applied our method to evaluate correlation between bathymetry and FA for South-East Brazilian coast which includes a part of the Vitoria-Trindade Fracture Zone (VTFZ).

\section{Metodology}

Our method is based on the assumption that similar morphology of two maps indicates correlation between mapped properties. We used three different criteria to evaluate morphological similarities: angular differences and cross-product. Gradient directions are determined according to Moore et al. (1993). Angles between gradients are measured from $0^{\circ}$ to $180^{\circ}$. According to our theory areas with small angular differences indicate morphological similarities or common tendencies. Averaged statistical distribution of angles may indicate the rate of correlation between maps. For correlated maps statistical dominance of small angles is expected. While for not-correlated data it is expected that angles values will tend to be equally distributed over the interval. A dominance of angles close $180^{\circ}$ would indicate inverse correlation.

The use of cross-product values for joint image interpretation was developed by Gallardo and Meju (Gallardo, Meju et al., 2003; 2004; 2005; 2007). Regions where cross-product values are minimized after multiplication are considered as correlated. Small crossgradient values imply either small amplitude gradients (i.e. "noise") or collinear gradients which is an indicator of morphological similarity.

In Table 1 we present summarized properties:

\begin{tabular}{|l|l|}
\hline $\begin{array}{l}\text { Angular } \\
\text { differences }\end{array}$ & $\begin{array}{l}\text { Measure morphological correlation } \\
\text { independently of gradient amplitudes. }\end{array}$ \\
\hline $\begin{array}{l}\text { Cross- } \\
\text { Product }\end{array}$ & $\begin{array}{l}\text { Depends on gradient directions and } \\
\text { magnitudes generating ambiguous results. }\end{array}$ \\
\hline
\end{tabular}

To reduce the ambiguity it is important to develop normalization and to analyze angles and magnitude maps. Gradient magnitudes were converted to percents to be comparable.

Statistical analysis was used to sort the data into two groups to reduce the ambiguity effect commented above and characterized numerically angles distibution: first group - gradients with magnitudes that could be considered anomalous (where the main minimizing source are the angles between gradients) and the second group - gradients with magnitudes that could be 
considered as background (where cross-product value is determined by the small magnitude independently of the angle). It was chosen to use the mean value and standard deviation (std) to sort the data in such two groups

\section{Models}

To test this method of evaluating correlations between bathymetry and FA we created two synthetic models simulating gravitational effect vertical component distribution. The first model is of the gravitational effect of a denser buried body not correlated with local bathymetry. The second model is of the gravitational effect of a prismatic bathymetric structure. For the second model we used two different depths from the estimation level in order to evaluate how the dispersion of the gravitational effect affects the shape of gradients field directions and cross-products values.

The results of these models indicated some interesting properties of the applied method. It had shown the importance of using different criteria to make the interpretations. As can be seen from Figure 1 for the first model the large spots of higher cross-product values were distributed randomly over the body not following the angles isolines thus suggesting no correlation between bathymetry and FA. Angles values did not indicated any correlation (Fig.1).

The second model showed that with increasing distance from the structure we can not expect the correspondence in shape between bathymetry and FA thus we can not expect the cross-product to minimize all over the structure even knowing that they are correlated. In the second model differently from the first the distribution on spots of the higher cross-product values follows the shape of magnitudes and angles isolines indicating a correlation between bathymetry and FA. While angles show a strong correlation by contouring structure borders by small values.

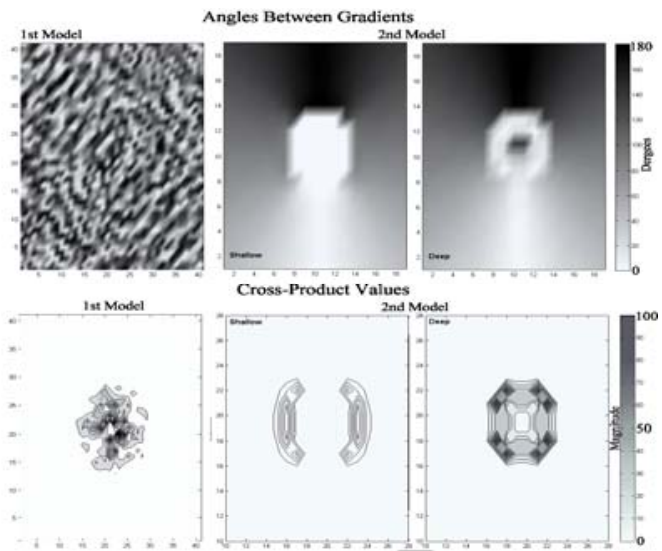

Figure 1 -Synthetic Models Angles and Cross-Product map.

Angles were equally distributed by intervals in the anomalous group indicating no correlation for the first model. While for the second showed a strong dominance of small angles.

\section{Application to South-East Brazilian Coast}

We applied this method to investigate the correlation between bathymetry and FA maps of the South-East Brazilian coast. The studied area is passive transition zone from oceanic to continental crust limited by $20^{\circ} \mathrm{W}$ and $30^{\circ} \mathrm{W}$ meridians and $15^{\circ} \mathrm{S}$ and $25^{\circ} \mathrm{S}$ parallels. According to the literature local bathymetry is complicated by volcanic seamounts and bank with a scale less than $100 \mathrm{~km}$ (except Abrolhos bank) those structures are expected to have a corresponding FA. (McKenzie, 1976, Zembruscki, S.G. 1979). The main tectonic structure is the Vitoria-Trindade Fracture Zone whit a corresponding seamount chain extending from east to west (Alves et al, 2006). This segment is characterized by regions with active and passive tectonics and a bathymetry with complicated relationship between isostatically compensated and uncompensated bathymetry with corresponding free-air anomalies.

The bathymetrical satellite data were derived from 2minute grid of the ETOPO2v2 obtained from National Geophysical Data Center (http://www.ngdc.noaa.gov). Marine gravity were obtained from the Satellite Geodesy at the Scripps Institution of Oceanography, UCSD (Smith \& Sandwell, 1997; http://topex.ucsd.edu).

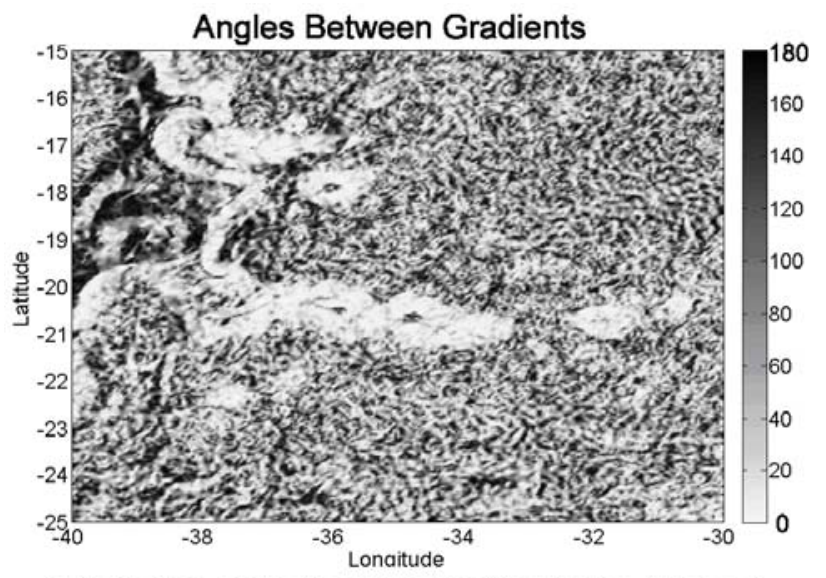

Distribution of Angles Between Gradients - General

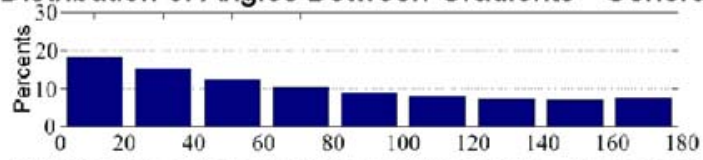

Distribution of Angles Between Gradients - Anomalous

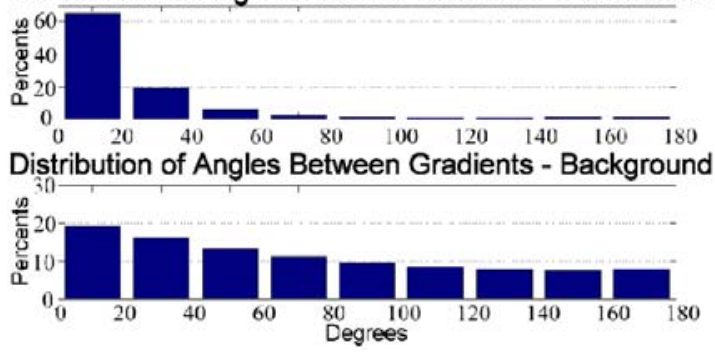

Figure 2 -Angles Map and Statistical Distribution. 
Figure 2 shows the map of angles between bathymetric and FA gradients and histograms of angles for all points, anomalous and background group. Statistical distribution of angles between bathymetric and FA gradient is given in equal intervals. Before statistical separation only $22.5 \%$ fell into the interval between $0^{\circ}$ and $20^{\circ}$. After statistical separation in the anomalous group almost $65.2 \%$ of the gradients between bathymetry and FA angles smaller than $20^{\circ}$ while in the background group just $19.2 \%$. Smaller angles are concentrated in the regions of significant bathymetric structures. Regions with no significant structures show uncorrelated spots indicating that bathymetry and FA is not correlated there.

Figure 3 presents the resulting cross-product map. It shows small spots of higher cross-product magnitudes following bathymetry and FA angles and magnitude isolines (as shown in second model). The background is characterized by small cross-product values, generated by small gradient magnitudes (thus it is not possible to make conclusions about correlations there). Some segments of the continental and some seamounts slopes are characterized by minimal values indicating a strong morphological correlation between gradient directions. According to these results for the studied area crossproduct values distribution shows good correlation suggesting that the bathymetry is the main source for the observed FA.

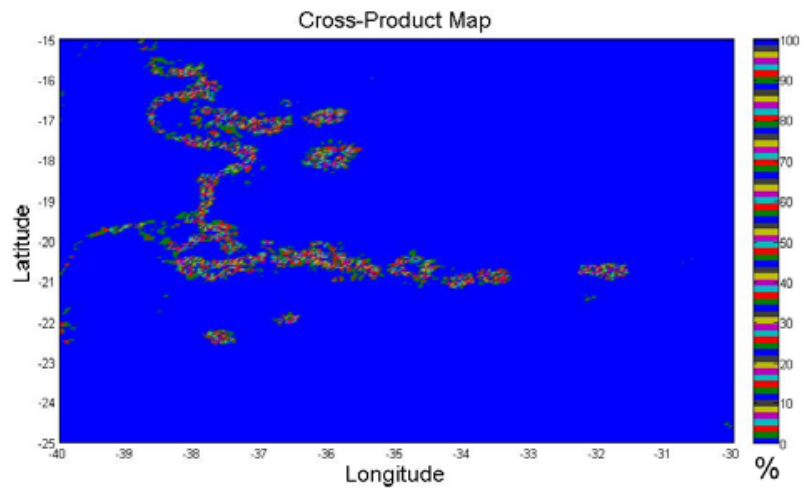

Figure 3 - Cross-Product Map

\section{Conclusions}

We used three different gradient properties to analyze the correlation between bathymetry and FA based on joint image interpretation of maps of the South-East segment of the Brazilian coast.

According to our results angles between gradients proved to be a good indicator of areas where maps are correlated and it is sensitive to small changes in gradient magnitudes. Maps of angles can be used to find areas with direct and inverse correlation between mapped properties and contour areas of influence of anomalies outside actual structure borders. A statistical analysis of the distribution of angles by magnitudes is a good criterion of correlation as show using our models and real data.

Cross-product is a good indicator of correlation. To reduce the problem of the ambiguity the analyses of angles proved to be helpful helping to separate the cross- product values minimized due to gradient magnitudes from those minimize due to angle values which are the indicator of correlation. Cross-product map also indicate a strong correlation between bathymetry and FA.

Based on our results we can conclude that for South-East Brazilian coast the bathymetry is the main source of the observed free-air gravity anomalies.

\section{Referências}

Dehlinger P., Marine Gravity, Elsevier, 1978.

Göttl, F., Rummel, R (2009), A Geodetic View on Isostatic Models, Pure and Applied Geophysics, Volume 166, Numbers 8-9 / September, 2009, 1247-1260.

Gallardo, L. A., M. A. Meju (2003), Characterization of heterogeneous near-surface materials by joint 2D inversion of dc resistivity and seismic data, Geophys. Res. Lett., 30(13), 1658, doi:10.1029/2003GL017370.

Gallardo, L. A., M. A. Meju, and M. A. Perez-Flores (2005), A quadratic programming approach for joint image reconstruction: mathematical and geophysical examples, Inverse Probl., 21, 435-452.

Gallardo, L. A., and M. A. Meju., Joint 2D cross-gradient imaging of magnetotelluric and seismic travel-time data for structural and lithological classification, Geophys. J. Int., 169, 1261-1272. (2007)

Gallardo, L.A., M. A. Meju (2004), Joint two-dimensional dc resistivity and seismic traveltime inversion with crossgradients constraints, J. Geophys. Res., 109, B03311, doi:10.1029/2003JB002716

Heiskanen, W. 1953. Isostatic reductions of the gravity anomalies by the aid of high-speed computing machines. Annales Academiae Scientiarum Fennicae, Series A, III. Geologica - Geographica, number 33.

Jakeman et al. editors, John Wiley and Sons, New York. Audet, P., Mareschal J.C. (2007), Wavelet analysis of the coherence between Bouguer gravity and topography: application to the elastic thickness anisotropy in the Canadian Shield, Geophysical Journal International, Volume 168 Issue 1, Pages 287 - 298

Jacoby, W., and Smilde P. L., Gravity Interpretation, Springer, 2009.

Keller, W., (2004)Wavelets in geodesy and geodynamics, ISBN 3-11-017546-0

McKenzie D. \& Bowin C. 1976. The relationship between bathymetry and gravity in Atlantic Ocean. Journal of Geophysical Research, 81: 1903-1915.

Moore, I. D., A. Lewis, and Gallant J. C., (1993), Terrain properties: Estimation Methods and Scale Effects, Modeling Change in Environmental Systems, A.J. 
Roy. K. K., Potential Theory in Applied Geophysics, Springer, 2008.

Smith, W. H. F., and D. T. Sandwell, Global seafloor topography from satellite altimetry and ship depth soundings, Science, v. 277, p. 1957-1962, 26 Sept., 1997.

Sandwell, D. T., and W. H. F. Smith, Global marine gravity from retracked Geosat and ERS-1 altimetry: Ridge Segmentation versus spreading rate, J. Geophys. Res., 114, B01411, doi:10.1029/2008JB006008, 2009.

TORGE, W., Geoda“sie (deGruyter Verlag, Berlin 2003).

Watts, A. B., Isostasy and Flexure of the Lithosphere, Cambridge University Press,. 2001

Zembruscki, S.G. 1979. Geomorfologia da Margem Continental Sul Brasileira e das Bacias Oceânicas Adjacentes. In: Geomorfologia da margem continental brasileira e das áreas oceânicas adjacentes. Série Projeto REMAC, $\mathrm{N}^{\circ} 7$. 